\title{
MIEDO, RISAS Y LEYENDAS URBANAS. LO FANTÁSTICO-HUMORÍSTICO EN INSTITUTOS DEL COLECTIVO CANICULADAS
}

\author{
José Manuel Trabado Cabado \\ Universidad de León \\ jmtrac@unileon.es
}

Recibido: 11-12-2020

Aceptado: 31-08-2021

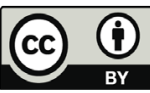

RESUMEN

Este artículo analiza la relación entre la poética del discurso fantástico y la del humorístico que tiene lugar en Institutos, obra del colectivo de creadoras de cómic conocido como Caniculadas. Ambos discursos comparten una estructura formal basada en el relato breve que finaliza con un giro argumental en el que encontramos una mezcla de efectos: terror y risa. Estos dos efectos operan, sin embargo, en diferentes niveles discursivos. Por una parte, en la estructura profunda existe una historia terrorífica basada en leyendas urbanas que son decodificadas desde una perspectiva irónica. Por otro lado, en el nivel más superficial, el lector encuentra un cierto tipo de broma que atempera el miedo causado por un relato insólito. Estas dos tendencias narrativas se solapan una sobre la otra creando un texto polifónico. Lo fantástico pervive como la huella de un viejo discurso heredado que ha sido renovado por una perspectiva femenina moderna y subversiva.

Palabras ClaVE: leyenda urbana; cómic fantástico; voz femenina; ironía.

FEAR, LAUGHS AND URBAN LEGENDS. THE FANTASTIC-HUMOROUS IN INSTITUTOS BY CANICULADAS

\section{ABSTRACT}

This article deals with the relationship between the poetics of the fantastic and the humorous discourses that takes place in Institutos, written by a collective group of 
women comic creators known as Caniculadas. Both of them share a formal structure based on a short tale ending with a plot twist in which we found mixed effects: terror and laughter. These two effects work, however, on different discursive levels. On the one hand, a terrifying story based on urban legends that are decoded from an ironic point of view appears in the very deep structure. On the other hand, at the most superficial level, readers find a sort of joke that tempers the fear caused by an uncanny story. These two narrative trends overlap each other making a polyphonic text. The fantastic structures and themes survive as a trace of an old inherited speech renewed by a modern and subversive female perspective.

KEYWORDs: urban legend; fantastic comics; female voice; irony.

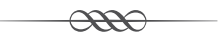

\section{INTRODUCCIÓN: GÉNERO NARRATIVO Y VOCES FEMENINAS}

Lo fantástico ha tenido un peso específico de primera magnitud en la trayectoria del lenguaje cómic (Gasca \& Gubern, 2015; Trabado, 2017a; Trabado, 2017b). Indudablemente, dentro de esa explosión del cómic adulto de los años 70-80 el cómic fantástico tuvo un gran desarrollo en un perpetuo e intenso diálogo con otros géneros como la ciencia ficción, el terror y la aventura. Lo fantástico permitía una liberación estilística y los autores podían hacer gala de unos grafismos de tremenda potencia visual que atrapaban la mirada del lector. Lo fantástico era, en muchas ocasiones, una política editorial que articulaba de forma coherente parte del material de aquellas revistas que acudían una y otra vez a géneros estables y perfectamente reconocibles por los lectores (Pérez, 2018). La evolución más reciente, sin embargo, de este lenguaje hacia propuestas más relacionadas con el relato de lo cotidiano y la forma de la autobiografía parecía presagiar un declive de esta temática.

Cabe preguntarse, dentro de ese entramado creativo de enorme vitalidad, qué papel desempeñaba desde la labor creativa la mujer. En una primera instancia, parece que ese papel resulta más bien secundario, ya que, dentro de ese denominado boom, las voces masculinas parecen las predominantes. ${ }^{1}$ Los géneros narrativos como la ciencia ficción y el terror acaban por deslizar un

1 Conviene tener en cuenta, desde la perspectiva de lo literario, los datos aportados por Patricia García (2019b) para calibrar la aparición de la mujer dentro de las antologías dedicadas a lo fantástico y la consiguiente elaboración de un canon. 
denominador común, al valerse de una representación del cuerpo femenino concebido como objeto de deseo. ${ }^{2}$ Esa iconografía erótica demandaba una mirada situada en el territorio de lo masculino. Aun con todo, la revista Totem en su número Extra 2 (1977) Especial mujeres abría una ventana a la posibilidad de plantear una especificidad discursiva para la voz femenina. Marika Vila, que formaba parte del elenco de creadoras incluidas en ese número, y que es autora también de un pequeño ensayo crítico titulado «Mujer, objeto y sujeto del cómic», muestra, en cambio, su malestar con lo que tilda como una estrategia un tanto cínica, atendiendo a lo que se argumentaba en la nota editorial. Allí se declaraba que, si alguna vez se había limitado la publicación de obras hechas por mujeres, era tan solo porque eran «demasiado avanzadas e innovadoras». Esa expresión, junto con el carácter de «excepcionalidad» de un número dedicado a las mujeres, declaraba la posición marginal de la mujer como creadora de cómics (Cortijo, 2011; Guiral, 2016; Vila, 2018). Conviene también plantear si el género narrativo asentado sobre estereotipos muy férreos, motivos temáticos codificados y con una iconografía ya modelada, al menos en el territorio del cómic, actuaba como elemento refractario a la incorporación de un mundo narrativo que diese cabida a una sensibilidad como la femenina, afinada en una tonalidad presumiblemente distinta (Richter, 1984; McCausland \& Salgado, 2019; García, 2019a). Si se acepta esa hipótesis podría explicarse el hecho de que existiese una mayor presencia de autoras de cómic en las revistas de carácter más experimental, asociadas al elemento contracultural del underground, que rehuían el género narrativo como marca editorial. En ese desplazamiento del cómic de género al cómic de autor se libera un espacio expresivo en el que podría ir inscribiéndose la voz femenina de forma paulatina. Autoras como Montse Clavé, Mariel Soria, la propia Marika Vila, Laura Pérez Vernetti, etc. canalizaron su producción esquivando los espacios ahormados por los géneros narrativos al uso. No solo esa reconfiguración venía del lado de la autoría, sino de la imagen de la mujer como personaje. Algunos autores como Miguelanxo Prado — pienso en obras como la serie Tangencias, Trazo de tiza o incluso Ar-

2 «El cuerpo femenino usado en la representación continuaba siendo un objeto que ninguneó aún más a las mujeres, no solo en el sentido clásico, sino al establecer un paralelismo en la superchería que igualaba su uso icónico a la libertad, pero lo que nunca se aclaró fue a la libertad de quién. / ¿Quién resultó liberado con el destape? En ningún caso las mujeres: estas solo aparecieron representadas como necesidad masculina (...) Para las autoras, esta fue una dificultad añadida con la que enfrentarse a la contaminación simbólica en la autorrepresentación» (Vila, 2018: 219-220). Si en 1977 ese número extra de Totem visibilizaba de forma problemática — y no exenta de polémica- la ausencia de la mujer en el mundo del cómic, Marika Vila refiere que, cuarenta años después —en 2017—, vuelve a un primer plano la protesta ante esa ausencia. Recuerda la denuncia llevada a cabo por Conxita Herrero, nominada al premio al Autor Revelación en el Salón del Cómic de Barcelona, que se hacía eco de la escasa presencia de mujeres entre los nominados a los premios del Salón. 
dalén - supieron modelar desde otra óptica los personajes femeninos, que dejaban de ser ese objeto de deseo para convertirse en un sujeto con enormes recodos emocionales. Precisamente ese rasgo podría ser un indicio, entre otros, del nacimiento de una conciencia plenamente desarrollada de autor. ${ }^{3}$

Los cambios radicales que tuvieron lugar a partir de la desaparición de aquel rico conglomerado de revistas en los años 90 fueron preparando la aparición de un nuevo horizonte editorial desligado ya del uso de los géneros narrativos. Surgen nuevas editoriales que toman el relevo y que inclinan su catálogo hacia obras de carácter más autoral, tal y como han estudiado perfectamente autores como Altarriba (2001: 307-327; 2008), Díaz de Guereñu (2011; 2014: 1755) o Antoni Guiral (2011). La intimidad se va adueñando del universo temático de la narración gráfica creando así un marco narrativo en el que la voz femenina se instalaba con naturalidad. No obstante, en ese contexto surgen también nuevas propuestas que, desde esa perspectiva profundamente personal, siguen dinamizando la idea de lo fantástico: son destacables las propuestas del ya mencionado Miguelanxo Prado (Trabado, 2019) o el caso singular de Luis Durán, en cuya obra, de poderosa personalidad y de ya dilatada producción, existe un constante apego a lo fantástico (Claudio, 2017; Díaz de Guereñu, 2019).

\section{LEYENDAS URBANAS: INTERMEDIARIO GENÉRICO Y POLÍTICA EDITORIAL}

Llegados aquí, resulta de interés examinar cómo puede verse el género de lo fantástico como una propuesta inducida dentro de un marco editorial. Un buen ejemplo de cómo una editorial puede propiciar la escritura de lo fantástico es la colección abierta por la editorial Astiberri que bautizaron como Leyendas Urbanas, en cuyo catálogo aparecen obras como Misterios comestibles (2014), de Albert Monteys, Videojuegos (2013), de David Sánchez, o Institutos, del colectivo de creadoras Caniculadas. ${ }^{4}$ Indudablemente, y a juzgar por las concomitancias

3 No solo en la tradición española puede establecerse ese paralelismo entre el cómic underground y más experimental y la autoría femenina. Ejemplos como los de Aline Kominsky, Phoebe Gloeckner, Lynda Barry, Marjane Satrapi, Alison Bechdel — por poner casos estudiados por Hillary Chute (2010)_ ayudan a consolidar esa relación entre el asentamiento del cómic realizado por mujeres y la consolidación de esa conciencia autoral.

4 «El webcómic fue básicamente una idea de Mireia [Pérez] en un momento en el que apenas había autoras de cómic conocidas, aunque después han ido saliendo mogollón, apareció la Asociación de Autoras de Cómic... Ahora hay mucha visibilización» (palabras de Natacha Bustos en la entrevista con Gerardo Vilches, 2016). Una muestra de esa visibilización de la mujer como creadora de cómic es la exposición Presentes: autoras de tebeo de ayer y de hoy, organizada y producida por la Agencia Española de Cooperación Internacional para el Desarrollo (AECID) en coordinación con el Colectivo Autoras de Cómic (España) en 2016. Fue comisariada por Elisa McCausland y Carla Berrocal (esta última integrante del colectivo Canicu- 
temáticas y los aspectos formales (tamaño 12x16, color bitono, 64 pp.), cabe trazar la hipótesis de que ha sido la editorial la que ha propiciado esas obras. Participan, además, de un mismo espíritu, consistente en la modernización del discurso fantástico a través de un intermediario como es la leyenda urbana. La adscripción a ese espacio de folclore integrado en la cultura de masas facilita en cierta manera su traslado al cómic. Existen casos anteriores de notable aprovechamiento de esas leyendas urbanas dentro del cómic. Pienso en la obra de Ricardo Barreiro Parque Chas, en la que lo fantástico urdido sobre los mimbres de la leyenda urbana permite ir trazando una serie de conexiones con la violencia ejercida por la dictadura argentina (véase Barreiro \& Risso, 2004), o en el caso de Belo Horizonte (2006) de Miguelanxo Prado, que sustancialmente propone un relato en cuyo núcleo misterioso se alojan referencias a una leyenda local que tiene, no obstante, precedentes en historias de la antigua tradición china.

Sin embargo, el uso que presentan historias como Institutos o Misterios comestibles aporta un tratamiento novedoso. Frente a la posibilidad de crear una gramática que, desde lo fantástico, afrontaba una realidad terrible (Barreiro en Parque Chas) o lo puramente misterioso-fantasmal que vehiculaba una relación amorosa (Prado), tanto Monteys como el colectivo Caniculadas ensayan un acercamiento que marca una profunda distancia irónica con respecto a esas leyendas urbanas. De la asunción discursiva de Prado y Barreiro se pasa al desapego de Monteys y Caniculadas. Esa distancia genera la posibilidad de ensayar un discurso irónico y a la par humorístico, que sirve para desmontar esa noción de lo fantástico entendido como discurso problemático en su descripción de la realidad y que, en su capacidad efectista, provoca incertidumbres y zozobras en los personajes que lo viven y, quizás y por extensión, en el lector. ${ }^{5}$ Ambas obras, tanto Misterios comestibles como Institutos, ofrecen una amalgama imprevista en la que el humor desnaturaliza el propósito desasosegante de lo fantástico. En cierta manera, actúan con una estrategia discursiva muy semejante. Tanto Monteys como Caniculadas citan esos discursos fantásticos, pero la cita que recoge y propaga de forma viral esos sucesos extraordinarios se hace desde una situación nueva e hilarante. Existe algo de rumor y cotilleo que se asume y se expande quitándole seriedad; en el

ladas), que recogía la muestra de 52 ilustradoras españolas en lo que se planteaba como un diálogo intergeneracional. El catálogo de esta exposición cuenta con textos de interés para una genealogía del cómic realizado por mujeres, tanto español (Guiral, 2016) como estadounidense (Merino, 2016).

5 A priori, y tal como señala David Roas, la unión de lo fantástico y el humor no debería funcionar: «emplear el humor entraría (aparentemente) en contradicción con los principales rasgos estructurales y pragmáticos que definen lo fantástico: introducir esa distancia frente a los hechos narrados haría desaparecer (...) la necesaria identificación que se establece en todo relato fantástico entre el lector y el personaje» (2011: 173). 
caso de Institutos, se hace desde un espacio inusual: los baños de un instituto en los que se reúne una serie de adolescentes para fumar porros y contarse historias de miedo. Se trata de una especie de heptamerón (son siete las autoras englobadas en ese colectivo creador) postmoderno en el que el desenfado dictado por la juventud de las narradoras y por la acción de los porros crea una red de relatos basados en el poder de una ouija, en los efectos de la ceniza en el alcohol, etc. Se genera, así, un inventario de terrores adolescentes, esclerotizados a estas alturas por la manida repetición. El humor se presenta entonces como una salida a ese cansancio de las repeticiones, siendo una forma de regenerar lo fantástico. Si esto se acepta, ver entonces el humor como una estrategia de desactivación de lo fantástico supone solo encarar una parte del problema; ${ }^{6}$ contra lo previsible, la risa no aniquila el miedo, sino que lo contiene y lo hace posible, aunque sea de forma irónica.

La ironía y el humor no eran, sin embargo, elementos que fuesen totalmente ajenos al sentimiento de lo fantástico en el territorio del cómic. Ya en la prensa norteamericana las páginas de Silas (pseudónimo que Winsor McCay utilizó para publicar su serie Dreams of the Rarebit Fiend) mostraban escenas en las que los personajes vivían momentos de absoluta angustia mezcladas con un elemento humorístico. La conjunción de terror y humor se conseguía situando lo pavoroso como la consecuencia de una pesadilla y lo humorístico como el resultado del contraste al regresar del mundo onírico a la realidad. La conjunción de elementos a priori tan dispares será también algo distintivo en los cómics de terror del mercado estadounidense. ${ }^{7}$ EC Comics puso en circulación en 1950 sus tres revistas dedicadas al terror: Tales from the Crypt, The Vault of Horror y The Haunt of Fear (véase EC Comics, 2019). El desarrollo del

6 Louis Vax ofrece un punto de vista interesante cuando afirma: «A primera vista, la ironía, el humorismo, son incompatibles con lo fantástico. Lo humorístico y lo fantástico se rechazan como el agua y el fuego. Cuando nos reímos de una historia de espanto, el espanto se disipa» (1965: 14). Sin embargo, observa ciertos puntos de contacto entre el humor y lo fantástico, afirmado, en primer lugar, que la risa ante lo fantástico nace como una actitud de defensa y advirtiendo, también, que la mezcla de lo vivo y lo inanimado era algo que estaba presente tanto en tiras humorísticas como en narraciones fantásticas. Recuerda, así mismo, que lo macabro y el humor negro eran algo muy del gusto de los surrealistas (1965: 15-16). David Roas, en cambio, advierte: «es necesaria una distancia (emocional) entre el lector y el objeto humorístico parar que la risa fluya libremente. Pero, de este modo, desaparece la necesaria implicación del lector en lo narrado que exige lo fantástico» (2011: 71). Todorov (1972) en su estudio clásico sobre lo fantástico no hace mención a la idea de lo humorístico como elemento problemático para lo fantástico. Las amenazas para lo fantástico provenían sobre todo del relato alegórico y de la poesía. Para una relación entre lo fantástico y el humor remito al número monográfico coordinado por Anna Bocutti (2018).

7 «Aunque EC fue la maestra en la aplicación del humor al terror, otras compañías, como Comic Media, Story, Ajax-Farrell, Superio y Charlton también emplearon ocasionalmente esta estrategia. En el extremo opuesto, esto es, con una aproximación severa al contenido de sus historietas, cabría destacar el planteamiento de la editorial Fawcett, una circunstancia paradójica teniendo en cuenta que el tratamiento desenfadado había hecho enormemente populares a sus superhéroes unos años antes» (Jiménez Varea, 2003: 92). 
terror no fue impedimento para la aparición de un elemento humorístico que dio una nota distintiva a este sello editorial: «EC horror comics usually had a tongue-in-cheek quality that gave them the character of a sick joke and diluted somewhat their atrocious implications» (Wright, 2003: 151). La editorial de cómics se valió de una estrategia tomada de los seriales radiofónicos que consistía en recurrir a ciertos personajes que actuaban como anfitriones y presentaban las historias de terror. Lo hacían desde una perspectiva humorístico-macabra ensayando, también, juegos de palabras en los títulos:

A la hora de introducir el humor en sus historietas, EC halló un valiosísimo aliado en la figura intratextual del host o anfitrión, un narrador intradiegético y, casi siempre, heterodiegético. Así cada una de las colecciones de horror de EC tenía su dibujante principal, también un anfitrión residente, si bien los otros ghoulunatics - así se llamaba en conjunto a The Crypt-Keeper, The Vault-Keeper y The Old Witch- aparecían también presentado historias más cortas. (...) En casi todos los casos, la función de los anfitriones era arropar la presentación y despedida de las historietas con chistes y comentarios sarcásticos (Jiménez Varea, 2003: 85-86).

William Gaines, co-fundador de EC comics, había dejado clara la intención humorística de los cómics de EC: «I love sick humor, and of course, the old EC stories were largely sick humor». El uso de estos anfitriones en las historias de terror no solo creaba un marco narrativo, sino que también ayudaba a realizar un balance final del relato justo en el momento en el que la trama narrativa daba un giro inesperado haciendo visible ese humor negro tan característico. Está idea será desarrollada más tarde por la editorial Warren en sus revistas: Uncle Creepy aparecerá como anfitrión en la revista Creepy en 1964, y en 1967 Cousin Eerie hará lo propio en la revista Eerie (véase Dark Horse Archives, 2009). Dos años más tarde, en 1969, verá la luz Vampirella, quien aparte de protagonizar su propia historia, seguirá con esa función de anfitriona. Se creaba, de este modo, una sólida tradición en la que el cómic de terror asociaba el humor al miedo a través de esa doble estrategia: el marco narrativo creado por el anfitrión y un giro final en el que, contrariando las expectativas lectoras, el presumible impacto causado por el argumento amalgamaba el terror con una nota ácida ${ }^{8}$ (Figura 1 ).

8 Esta fórmula fue tan importante que autores como Richard Corben la emplean en sus inicios. Valga de ejemplo el caso de la historia titulada «El amor del cojo Lem», en el que sigue presente aquel modelo del narrador/anfitrión: en ese caso «Gurggy Tate». Esta historia había aparecido en el número 2 de la revista Skull y, en España, se publicará en el primer número de la edición española de Creepy, publicada a partir de 1979 por Toutain. 


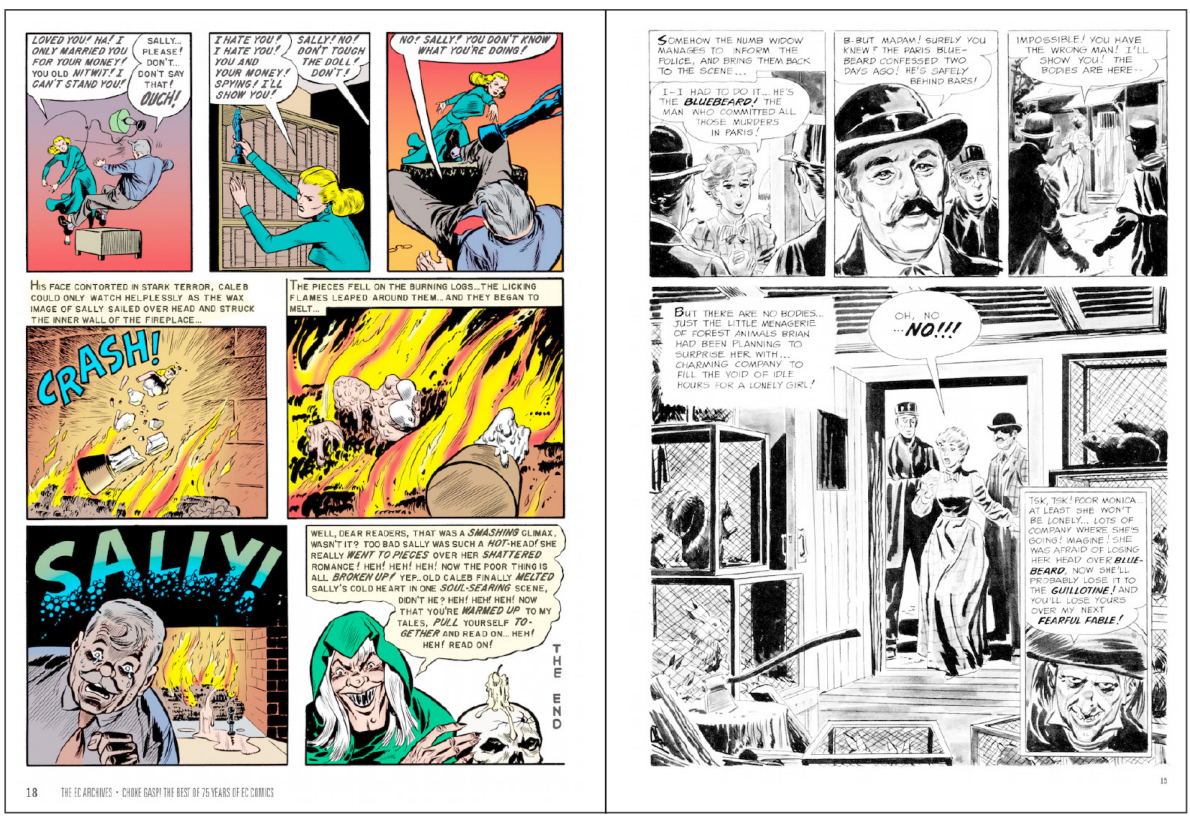

Figura 1. Página final de la historia «Woodoo Vengance» de Johnny Craig publicada originalmente en The Vault of Horror \#14 EC Comics (Izquierda).

Derecha: Página final de la historia de «Image of Bluebeard» publicada en el primer volumen de Eerie (Warren). En ambas se ve la relación entre el giro argumental final y la intervención del anfitrión.

En el caso de Institutos podría verse una doble influencia: a la férrea tradición del cómic de terror (que había inoculado ese humor negro en sus historias ya desde los años 50) habría que sumarle esa revisión postmoderna en la que lo fantástico se mostraba con cierta distancia. Esta forma de actuar está en consonancia con lo que venía sucediendo en el ámbito literario, en el que la ironía y la parodia se usaban también como estrategias para potenciar el carácter subversivo del relato fantástico: «la ironía y la parodia son, por tanto, dos formas de dar nueva vida a recursos, temas y tópicos sobreexplotados tanto en la literatura como en el cine fantásticos» (Roas, 2011: 175). ${ }^{9}$

9 Revisten interés las palabras de George Suarez reproducidas por Jiménez Varea (2003: 84): «el horror serio tiene que estar muy bien hecho para poder disfrutarlo. El horror mediocre o malo aún se puede hacer interesantes si se inocula un elemento de humor al contar la historia (...) Bill Gaines y compañía sabían que no podían producir más de dos docenas de historias de horror de máxima calidad cada dos meses. Al acercarse de manera burlona al relato de horror, desviaban la atención del lector del uso de fórmulas argumentales y otros atajos que empleaban para cumplir los plazos de entrega». 
Si analizamos, en cambio, la naturaleza estructural de los diversos relatos realizados por Caniculadas para Institutos, podríamos ver inscritos en su estructura narrativa los modos tanto del gag humorístico como del relato fantástico. Tanto es así que esto lleva a preguntarse si no es posible establecer un posible paralelismo entre ambos modelos estructurales. Ese parentesco formal entre el chiste y el relato fantástico nos ofrece una estrategia que permite conciliar esos dos modos discursivos aparentemente enfrentados.

Es de gran interés la caracterización que realiza Noël Carroll de los chistes:

$x$ : is a joke if and on if (1) $x$ is integrally structured, verbal discourse, generally of the form of a riddle or a narrative (often a fantastic narrative), (2) concluding with a punch line, whose abruptly puzzling nature, (3) elicits, usually quite quickly, a determinate interpretation (or determinate range of interpretations) from listeners, (4) which interpretation solves the puzzle and fits the prominent features of the riddle or narrative, but (5) involves the attribution of the least one gross error, but possibly more, to the characters and/or implied tellers of the riddle or narrative, and / or involves the assumption of the at least one such error by the implied or actual listener, (6) which error is supposed to be recognized by the listener as an error (2003: 329).

La brevedad del chiste, la organización narrativa en la que se alude a la posibilidad de lo fantástico, el final abrupto y sorprendente, la ambigüedad interpretativa son elementos que pueden crear un paralelismo formal entre el chiste y el relato fantástico. Resulta significativo, precisamente, el hecho de que entre las jóvenes protagonistas exista la posibilidad de contar chistes o historias de miedo (Caniculadas, 2014: pp. 26-27), lo que da buena muestra de esa imbricación de esos dos modelos compositivos. ${ }^{10}$

Puede aventurarse, atendiendo a esta sintonía estructural, que en los microrrelatos de Caniculadas el chiste y el relato fantástico entrelazan sus modos expresivos alternándose y estableciendo un diálogo continuo. Cada modelo constructivo especializa su efecto propio sobre los receptores: o bien el miedo y la zozobra (relato fantástico) o bien la risa (chiste). Ambos, sin embargo, no actúan en el mismo nivel enunciativo.

No solo el contexto situacional del relato (las adolescentes protagonistas se refugian en los baños del instituto para fumar y narrar misterios) desmantela su efectividad, sino que las interrupciones, el estilo de los personajes que hablan como adolescentes alocadas, el dibujo caricaturesco son

10 Sobre la sintaxis narrativa del relato de terror remito a las interesantes páginas de Noël Carroll (2005: 209, 326) 
indicios de ese explícito humorismo con el que se encara el relato fantástico. Esto se ve a la perfección en el transcurso de la historia «Pequeñas criaturas del mal», a cargo de la Srta. M. (Manuela López). En ella la adolescente narradora, tras las insistentes peticiones de que cuente algo de terror, inicia su historia de forma grandilocuente y, a la vez, humorística: «Vosotras lo habéis querido... Os contaré una historia con la que os haréis caquita». El rótulo en el que aparece simula (de manera casi burlesca) las tipografías de las historias del cómic de terror. Se trata, evidentemente, de una cita irónica. Cuando el relato comienza las interrupciones suponen una maniobra que socava el potencial perturbador de la historia. Le animan a que «no se enrolle» y siga con el relato. Cuando describe a la protagonista y destaca su elemento característico —el pelo ${ }^{11}$ — e inmediatamente le preguntan «de qué parte» $\mathrm{y}$, al afirmar que era la mejor de la clase en los estudios y los deportes, alguien comenta que la odia (Figura 2).

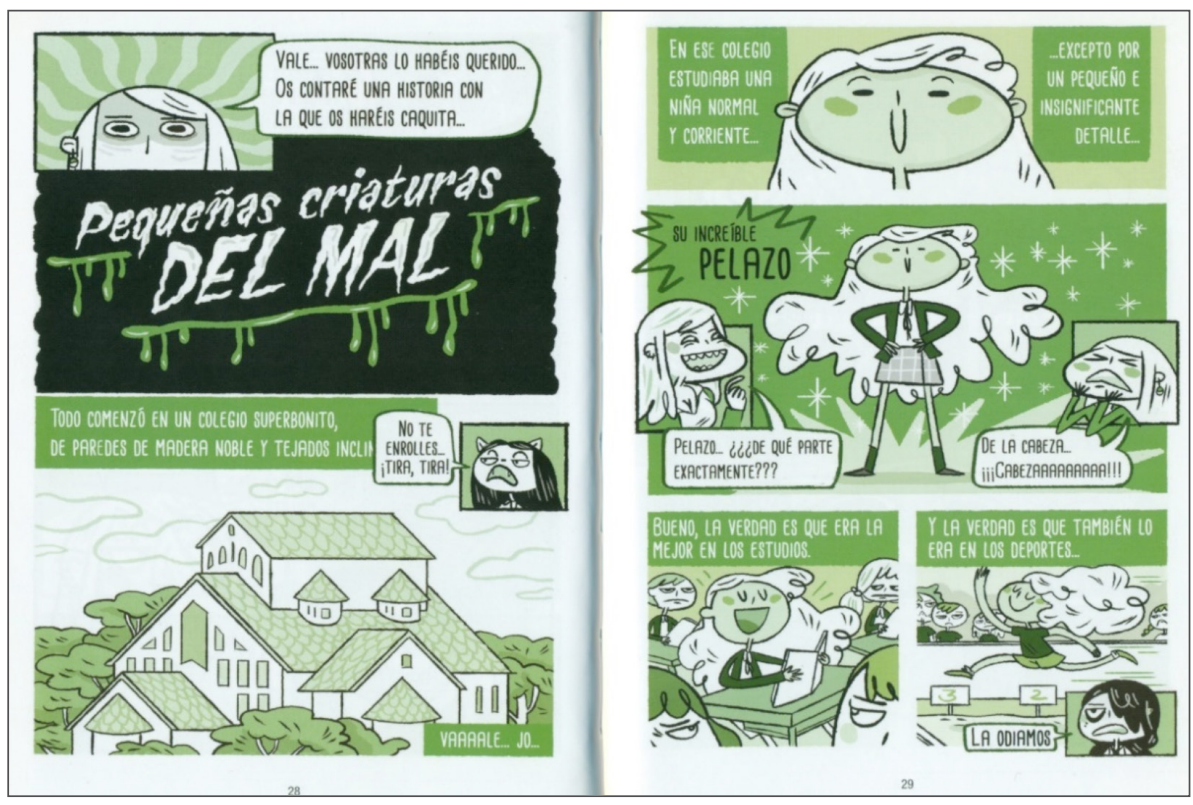

Figura 2. Doble página de Institutos en la que se pueden ver los comentarios de los otros personajes que interrumpen desde una óptica humorística el relato de terror.

11 Resulta tentador pensar en el libro Pelos (2016) publicado por otro colectivo de mujeres, Microlocas. Se trata de una colección de microrrelatos que orbitan en torno al pelo y la búsqueda de la identidad femenina. Existen, pues, algunas concomitancias, aunque sean parciales - como la coincidencia temática o la conciencia colectiva creativa femenina- entre Caniculadas y Microlocas. 
A cada frase la narradora obtiene un comentario que anula esa burbuja que necesita el cuento de terror para crear un ambiente tenebroso, por lo cual ella no será capaz de establecer una tensión en la narración y su auditorio de compañeras la acusarán de contar «una mierda de relato» y de que las está timando. Cierto es que el auditorio estaba predispuesto a diluir lo terrorífico a través de un humorismo cínico incapaz de creerse lo contado como historia de terror. Cuando finalmente pone en escena cuál es el elemento perturbador - una oruga que vive en los árboles del patio y que devora la melena de los alumnos-, la imagen posee una profunda naturaleza caricaturesca muy lejana del estilo gráfico del cómic de terror (Figura 3).

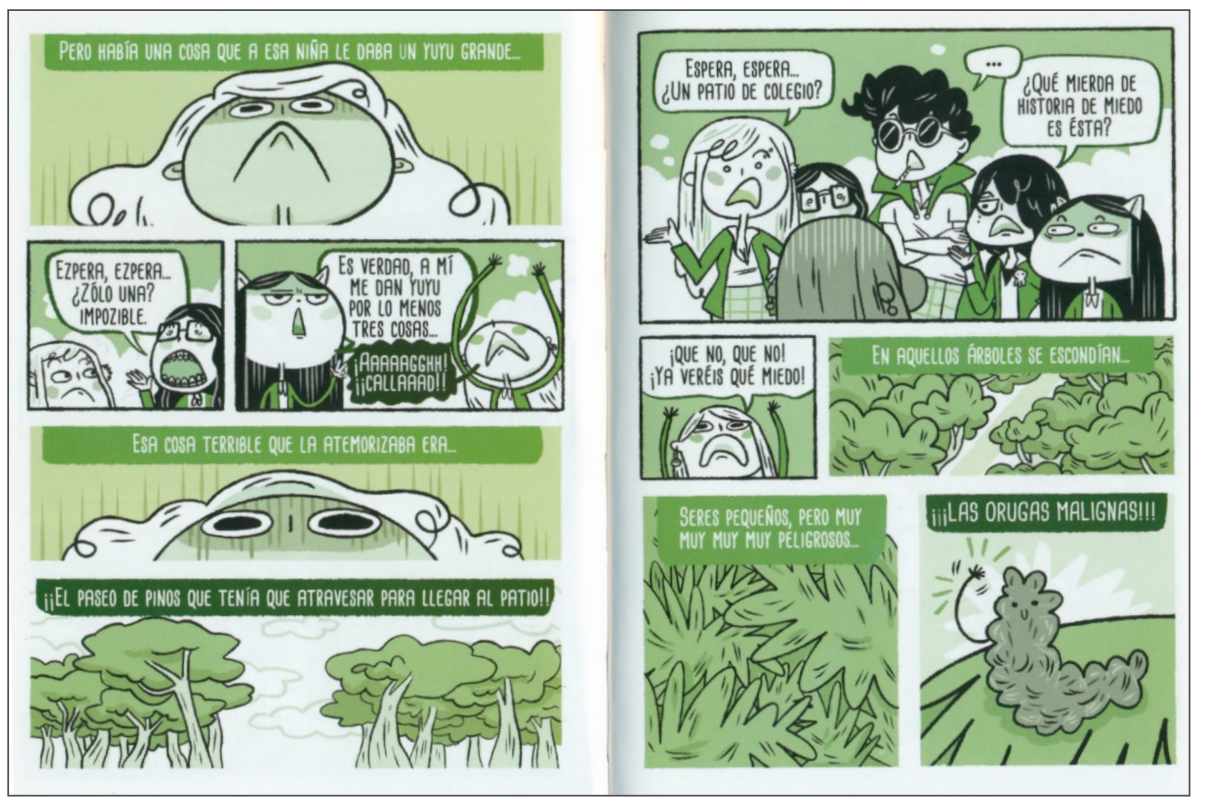

Figura 3. Doble página de Institutos en la que el estilo caricaturesco aleja el relato de los cánones gráficos del terror.

Sin embargo, si en el planteamiento y nudo del relato todo obedecía a una actitud burlona hacia lo esencialmente terrorífico, el desenlace supone una vuelta de tuerca y un cambio de actitud. Existe un golpe de efecto perfectamente calibrado. Cuando la protagonista llegue desesperada por su calvicie para comunicárselo al resto de la clase, observará que todos sus compañeros están también calvos. Lo realmente desasosegante es la cara de normalidad que presentan frente a la angustia de la protagonista. Toda esa ominosidad explota en una escena 
que ofrece un hondo impacto en aquel grupo desenfadado de colegialas que venían burlándose de la historia que estaban oyendo. Si hacemos un balance del funcionamiento de los elementos narrativos, obtenemos que tanto en el planteamiento como en el nudo la narradora está valiéndose de los motivos temáticos del relato de terror. Frente a esa estructura narrativa, se erige una actitud burlona por parte de su auditorio que no se cree lo que oye. En esos momentos existe un empuje de lo irónico sobre lo terrorífico. Precisamente, cuando el relato se precipita hacia su resolución se instala ese giro imprevisto compartido por chiste y relato fantástico. Mediante ese truco argumental se produce un vuelco. Desde ese punto de vista estructural podría hablarse de una suerte de shifter interdiscursivo, por el cual el relato terrorífico toma el relevo de la ironía distanciada del relato humorístico. El descreimiento del auditorio se torna en una honda impresión que deja sin palabras a quien antes se estaba burlando. Así, pues, si atendemos a las intenciones del personaje narrador y al efecto que causan sus palabras, podemos observar que el relato nacía originariamente bajo los auspicios del terror, pero no conseguía su propósito. Existía un fracaso comunicativo canalizado a través de las burlas, pero, finalmente, acaba imponiéndose y logrando con creces lo que pretendía: provocar miedo. Ese relevo entre el humor/terror opera, no obstante, solo y exclusivamente dentro del nivel intradiscursivo, es decir, en las relaciones entre los personajes que habitan ese universo ficticio.

Es legítimo preguntarse si esa idea es extrapolable a un nivel extradiscursivo, esto es, si el lector experimenta el mismo comportamiento que el auditorio interno. La hipótesis más plausible es la de pensar que ese cambio entre humor que deriva en terror y la subsiguiente mutación de la risa en miedo que tiene lugar dentro de la esfera de la ficción no se refleja en la presumible reacción del lector. Este entiende desde un primer momento que toda la tramoya terrorífica es solo un manido amasijo de tópicos contados por adolescentes que entretienen sus tiempos muertos con estas historias de miedo. Cuando se produce el golpe de efecto final, su reacción es de un signo bien diferente a la de las adolescentes repentinamente enmudecidas. Mientras ellas cambian de actitud, el lector disfruta de ello y puede experimentar un incremento de su reacción ante lo humorístico. El cambio repentino de aquellos comentarios burlones en silencio atemorizado ha de provocar risa en el lector. El efecto de lo fantástico, aun sin desaparecer del todo, acaba diluyéndose en una reacción ante lo cómico de la situación. Quedan rescoldos de ese miedo ante la nueva situación, pero no deja de ser algo secundario, un vestigio apenas insinuado. Dicho de otra manera, lo que para el resto de chicas supone un final lleno de congoja para el lector acarrea la posibilidad de un final risible. Los distintos niveles discursivos generan 
efectos bien diferentes. El lector no deja de ver una historia de cariz cómico que se vale de los resortes de lo fantástico, pero se trata de un tipo de relato fantástico citado y no asumido vitalmente. Por esa razón no causa esa inquietud. Para los personajes, sin embargo, todo cambia y ese giro argumental los sume en una profunda perplejidad. Lo que en su momento era objeto de burla encerraba un potencial perturbador que funcionaba subterráneamente. Habían subestimado el horror implícito que escondía el relato de su compañera. Esa inocencia de unas y otras genera en el lector una complicidad cómica en la que el relato fantástico queda subsumido por otro discurso (el humorístico) que, al compartir una articulación formal semejante, podía alojarlo de manera eficaz (Figura 4).

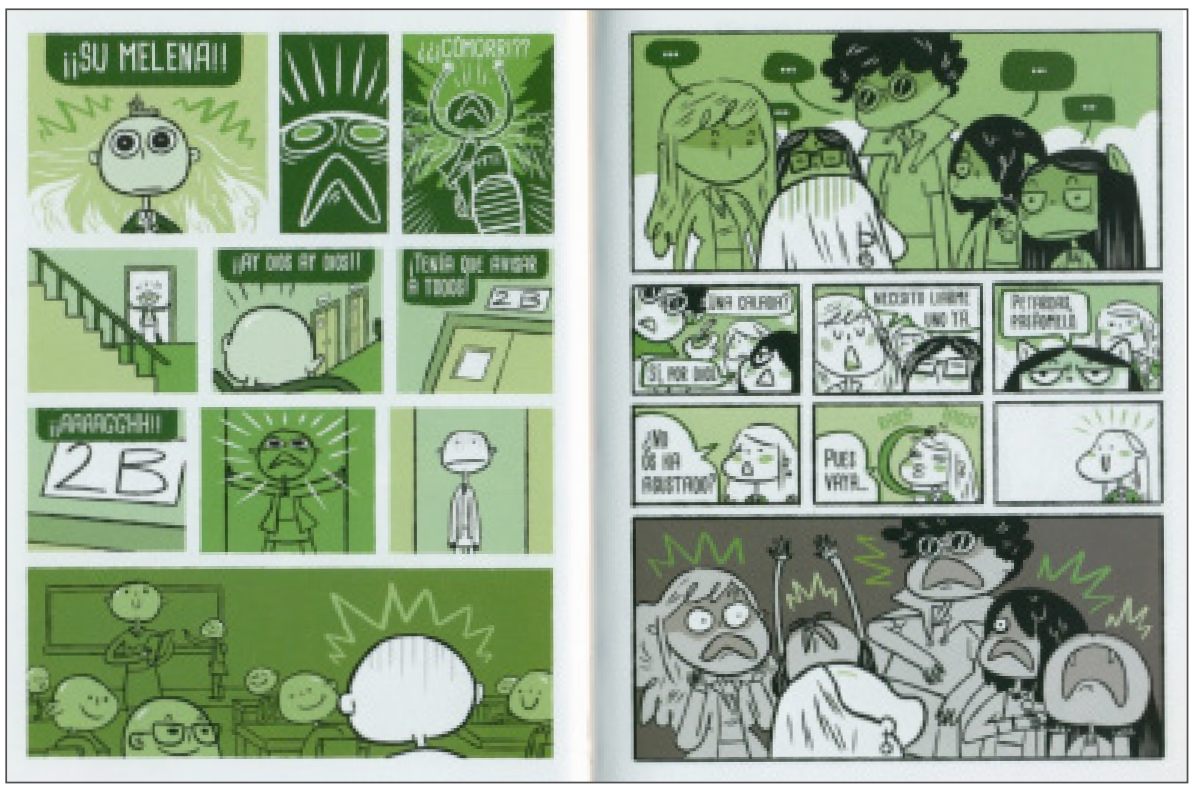

Figura 4. Doble página de Institutos en la que se puede ver la confluencia entre lo humorístico y lo fantástico.

Cada relato de Institutos puede ser entendido como un gag extendido que aloja en su interior las ruinas de un relato fantástico que ha sido desmontado a través de una doble operación: una, de naturaleza interna al propio relato, por la cual los personajes opinan, interrumpen y se ríen de cada historia; otra, de signo diferente y cuyo marco de actuación proviene de una operación autoral, consistente en reasignar nuevas funciones a los elementos constitutivos del relato terrorífico para alojarlos en un nuevo recipiente como es el relato humorístico. 


\section{HUMOR Y TERROR. LA HIPÉRBOLE EN CANICULADAS}

La simbiosis entre el discurso humorístico y el relato de terror no es algo específico de Institutos. Esta idea la podemos ver expresada también en una de las entradas del web cómic Caniculadas. Se trata de la titulada «Los lunes de mierda II: CLIENTES DE MIERDA», del 27 de julio de 2015 realizada por Andre (Torrejón, 2015) (Figura 5). En ella se narran algunos de los temores más profundos del ilustrador/a freelance, que tienen que ver con las fechas de entrega y los retoques que impone el editor autoritario al artista. Todas esas obligaciones contraídas son vistas con pánico por el ilustrador y, por esta razón, junto con los textos aparecen ilustraciones que se basan en guiños a las portadas de las revistas pulp de terror. En esas portadas redibujadas en el web-cómic los textos originales que aludían a los elementos góticos son sustituidos ahora por referencias a los plazos inapelables o exigencias del editor: «Está perfecto pero cámbialo todo», «La Deadline adelantada». Esas alusiones encubren un homenaje admirativo a esa cultura popular, pero, al mismo tiempo, establecen la posibilidad de asumir discurso ajeno para hablar a través de él de la esclavitud que comporta el trabajo creativo para un tercero. Es, por así decirlo, un discurso polifónico. En el seno de esa polifonía existe una disonancia nacida de la distancia entre lo terrorífico del pulp y la anécdota cotidiana. Precisamente es este hecho el que crea un efecto humorístico. La transformación de lo cotidiano en terror no se consigue a través una desfamiliarización, según era habitual en lo fantástico clásico, sino a través de la hipérbole, algo más en consonancia con lo fantástico-humorístico.

Por otra parte, la alusión a ese carácter tétrico le permite, a su vez, generar una vía de escape a través de la naturaleza del texto digital: la creación de un enlace para remitir a todo un catálogo de portadas de revistas. El cómic digital posee, en cuanto hipertexto, una naturaleza de corte centrífugo. Es un texto que no tiene por qué formalizar sus fronteras dentro de él. El discurso gráfico que asume los estilemas de terror es a la vez una forma de intertextualidad que opera dentro del discurso, pero también un punto de llegada en la que la entrada de Caniculadas es un intermediario. No es este un ejemplo solitario. Pueden rastrearse otros casos en los que alguna de las autoras de Caniculadas se vale de la imaginería del terror para contar y dibujar episodios cotidianos. El discurso terrorífico se ciñe exclusivamente a lo gráfico y surge como el resultado plástico de un suceso cotidiano que causa un malestar en las protagonistas y lo convierten en una hipérbole desmedida que se vale del repertorio gráfico del terror (Figura 6). Así, el verano con sus quemaduras y 
accidentes o los souvenirs que traen los conocidos como prueba palpable de sus vacaciones estivales configuran un nuevo universo terrorífico en manos de Bea Tormo y Natacha Bustos. La experiencia de Caniculadas basada en la visión desenfadada de la realidad creó - a través de una retórica basada en la hipérbole- la posibilidad de valerse de un discurso genérico que calcaba algunos de los elementos del relato de terror. Terror y humor caminaban de la mano en el mundo digital de Caniculadas, pero no establecían una relación dialéctica, como sucederá en Institutos. Lo terrorífico era una prolongación deformada de lo cotidiano a través del humor. Desde esta perspectiva podría decirse que Caniculadas se convertía, así, no solo en un divertimento veraniego, sino en un laboratorio en el que comenzaban a unirse los ingredientes necesarios que acabarían cristalizando en la fórmula de lo fantástico-humorístico de Institutos, fórmula que venía, dicho sea de paso, propiciada por la filosofía de la colección «Leyendas urbanas», de la editorial Astiberri.

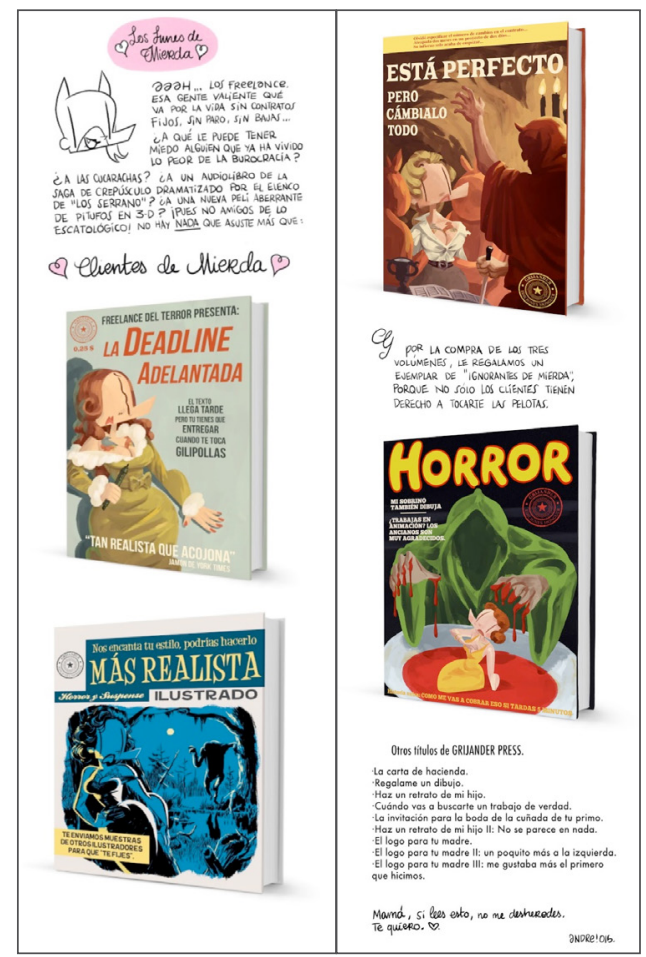

Figura 5. Entrada del blog de Caniculadas realizada por Andre en la que se utiliza el código gráfico-narrativo del relato de terror para referir una experiencia cotidiana desde una óptica humorística (véase Torrejón, 2015). 


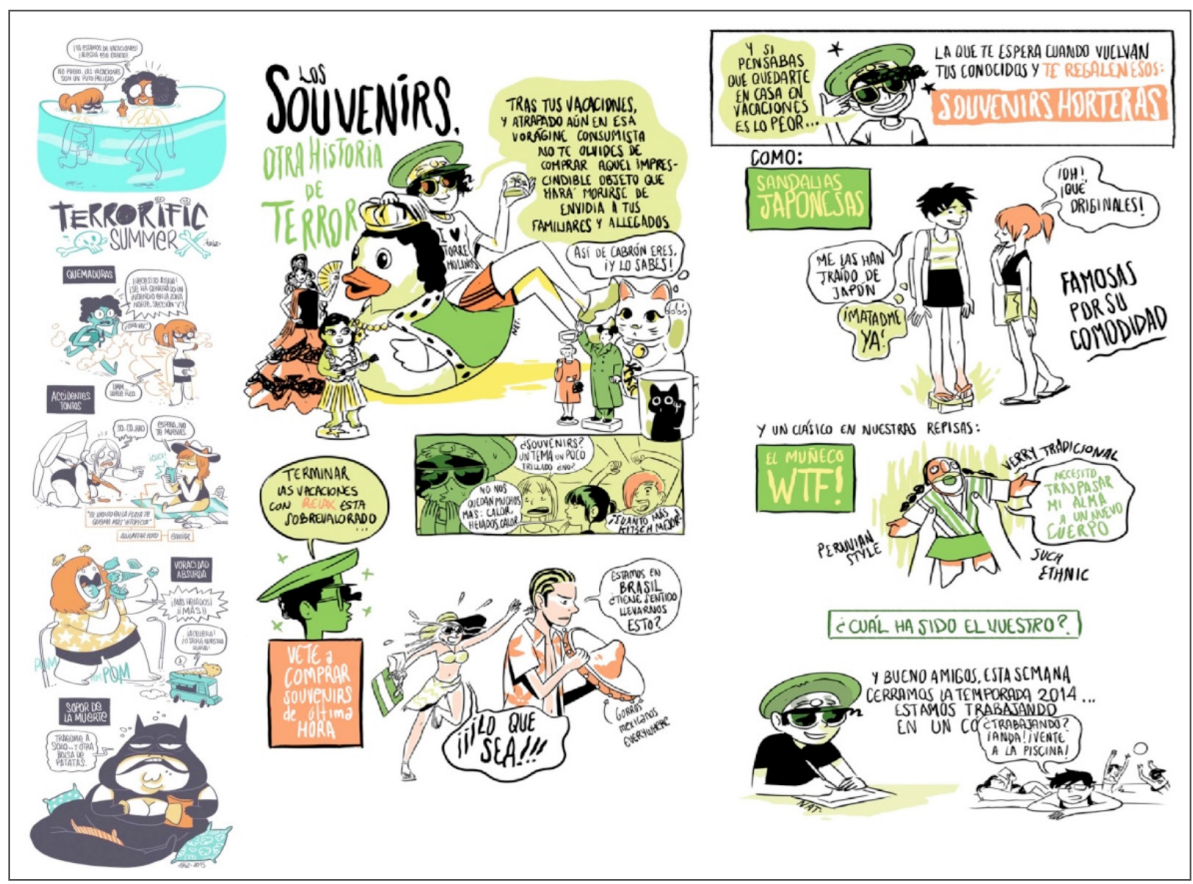

Figura 6. Sucesos cotidianos que son relatados desde una óptica terrorífica a través de la hipérbole humorística. A la izquierda una entrada de Bea Tormo de Caniculadas que corresponde al 14 de agosto de 2015. A la derecha, parte de la entrada del 12 de agosto de 2014 realizada por Natacha Bustos.

\section{LA KOINÉ GRÁFICA EN INSTITUTOS}

Si enfrentamos, no obstante, la capacidad centrífuga tanto temática como estilística de los diversos posts del blog Caniculadas con lo realizado en el libro Institutos observamos una diferencia sustancial. ${ }^{12}$ A pesar de que se mantiene en el libro esa actitud humorística y desenfadada del blog, existe una suerte de doble imposición que sirve para reajustar esa dispersión propia del blog colectivo hacia una convergencia estilística demandada en el libro: de un lado, la leyenda urbana apuntalaba tanto la coherencia temática como estructural y, de otro, el estilo gráfico buscaba aunar las diferentes personalidades limando aristas para engastar las diferentes historias en un úni-

12 Para una visión panorámica sobre el cómic digital en España remito al trabajo de José Antonio Serrano (2016). Sobre la posible innovación que pudiera aportar el cómic digital es de gran interés el trabajo de Rubén Varillas (2016). 
co relato. La disparidad estilística dentro del relato gráfico fantástico es muy apreciable en un caso como el de Carla Berrocal. En 2011 esta autora publicó una historia titulada El Brujo. La obra posee un sello autoral muy marcado que le permite desarrollar la idea de lo fantástico basándose en leyendas chilenas que conocía a través del libro de Umiliana Cárdenas Casos de Brujos de Chiloé. Se trata de un tipo de relato fantástico que podría denominarse como lo fantástico arraigado, ya que hunde sus cimientos temáticos en historias folclóricas. Esta configuración de lo fantástico supone una búsqueda de la identidad en la que suelen intervenir móviles emocionales. Es, por ello, un tipo de historia conectada con un territorio y una memoria que, en ocasiones, puede tener resonancias familiares.

En El brujo, tras un estilo gráfico que asumía innumerables registros, Carla Berrocal narraba la historia de Porfirio Pillampell, que emprendía un camino trufado de etapas con el que pretendía renunciar a su condición de mago. En su origen está anclada una historia de naturaleza traumática y cada fase en la que el protagonista pretendía restituir valores como la justicia, el amor o la verdad — haciendo alarde de su capacidad sobrenatural para alterar y corregir los caminos errados- venía modelada sobre un estilo gráfico radicalmente diferente. Más allá del portento de versatilidad que demuestra la capacidad técnica de Carla Berrocal, interesa señalar su rendimiento narrativo. Cada etapa elige un estilo diferente: al placer inmediato del deleite visual se une un deleite intelectual y narrativo. En todo caso, la conclusión es que Carla Berrocal desdibuja el carácter monolítico del narrador gráfico a través de un estilo poliédrico y cambiante (Figura 7). Frente a ese «fantástico arraigado» de El brujo, Institutos presenta otra caracterización sustancialmente diferente de lo fantástico.

El folclore mágico chileno deja paso al inventario viralizado de las leyendas urbanas que poseen una naturaleza deslocalizada por cuanto que borran su origen. Su ubicación reside en lo que podría denominarse ese «no-lugar» de la tradición oral que se ha traspasado a los entornos digitales.

En su contribución a Institutos, Carla Berrocal inhibe su repertorio gráfico con el fin de ajustarse a esa koiné gráfica que viene mediatizada por necesidades tanto editoriales (de carácter externo) como narrativas (de carácter interno).

A todo ello hay que añadirle la cuestión enunciativa. Mientras que en El Brujo existe un narrador externo y un «grafiador» cambiante, en el blog Caniculadas Carla Berrocal, al igual que sus compañeras, construye un alter ego gráfico que supone una representación distorsionada y humorística, una suerte 

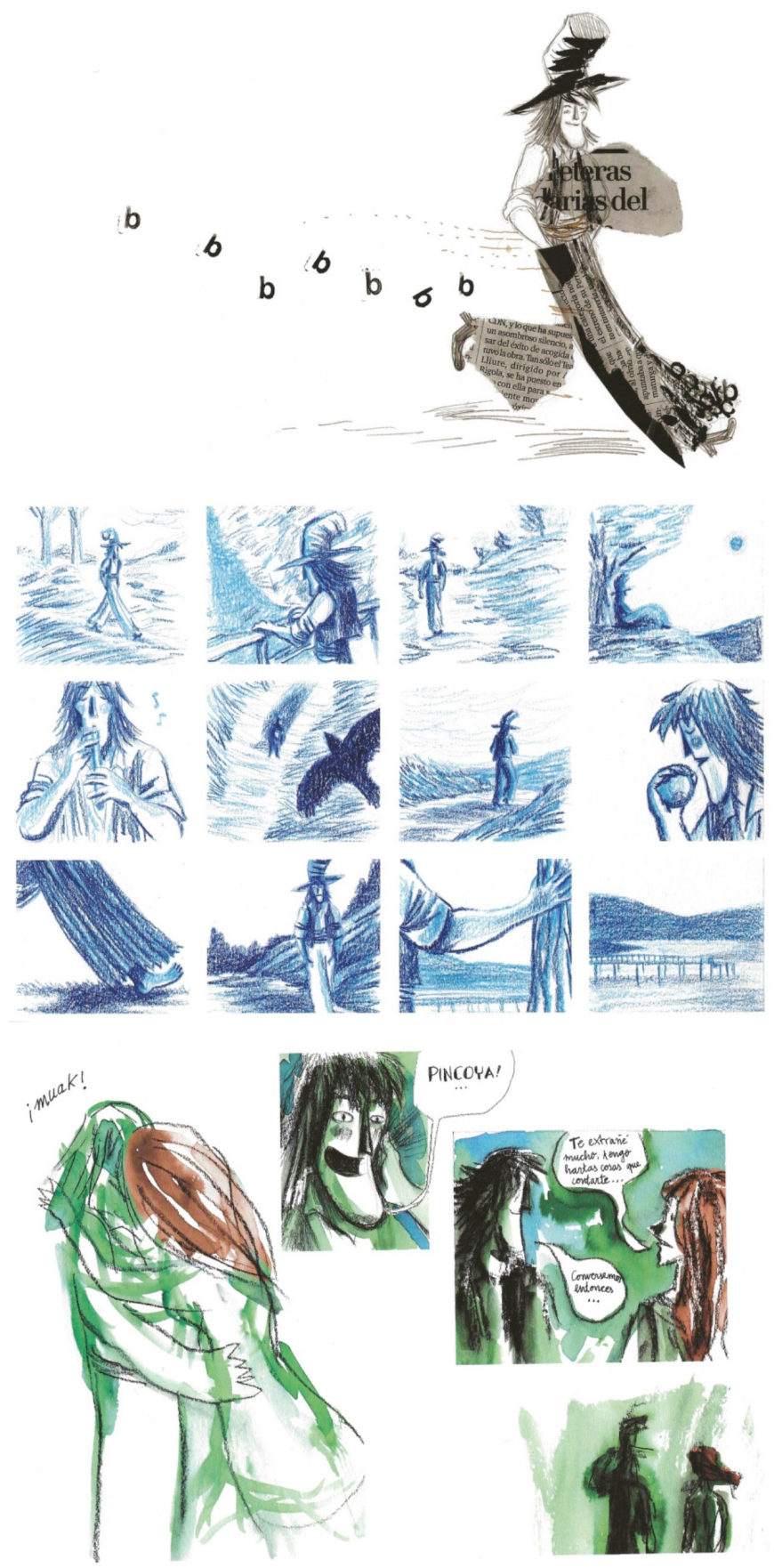

Figura 7. Variedad estilística dentro de El brujo, de Carla Berrocal. 
de superheroína enmascarada llamada Carlis. Este avatar gráfico aparece al principio y al final del relato de Institutos, pero el cromatismo del bitono basado en verdes y negros obedece a esa necesidad de buscar un engaste estilístico entre las distintas autoras.

Así pues, frente al estilo como marca singularizadora de una conciencia autoral de El brujo, materializado en un abanico gráfico de enorme variedad, Carla Berrocal accede al espacio común de creación de Caniculadas que podría ser caracterizado como un ágora, un punto de encuentro en el que los estilos han de conjugarse para crear (al menos en el libro de Astiberri) un relato legible. Existe una planificación conjunta en la que cada autora narra una historia de «miedo» a través de su alter ego gráfico. Resulta sugerente albergar la hipótesis de que la mirada conjunta del colectivo Caniculadas busca desmontar los discursos recibidos (la leyenda urbana) a través del humor. Esa deconstrucción se cifra en constantes interrupciones que provocan una deflación del miedo intrínseco del relato de terror. Su desenfado, no obstante, también camufla una visión distanciada de cada autora con respecto a su «avatar gráfico». Se trata de un ejercicio paródico y de distanciamiento no solo del género de la leyenda urbana, como resulta del empuje del humor y descreimiento femenino adolescente, sino también de cada autora con respecto a los personajes femeninos que allí hablan. Otra modalidad subversiva tiene lugar, a su vez, cuando las adolescentes acaban amedrentadas ante la deriva final de los acontecimientos y, en consecuencia, la risa inicial se torna en mudo espanto. En este caso estaríamos ante una fuerza contraria: será la acción de terror la que incida sobre la actitud burlona del grupo de adolescentes fumadas que se encierran en el baño del instituto.

Cabe, pues, pensar a estas alturas en cómo se integra dentro del espacio editorial la creación del colectivo Caniculadas. Su nacimiento emana de un territorio periférico y al margen de las estructuras del mercado y los intermediarios editoriales. El espacio digital proporciona sus propios formatos expresivos. Las breves entradas del blog a modo de post ofrecían el crisol ideal para la historia breve y de carácter humorístico. Existe una ecuación que, en el caso de Caniculadas, iguala el post del blog (formato digital) y el chiste gráfico (estructura discursivo-textual). El éxito de ese blog permitió la «migración» de plataforma: del entorno digital (siempre cambiante y desterritorializado) se pasó al ingreso en las estructuras de mercado presidido por políticas editoriales que segmentan y buscan un público. Del espacio digital que invita a una construcción vertical de historias que deben ser leídas haciendo scroll con el ratón, el relato debía confinarse a la férrea estructura del libro que, además, por diseño editorial, poseía un tamaño reducido. Lo evanescente y disperso 
del espacio digital se transforma en la sólida cárcel del formato libro. Caniculadas retuvo en parte ese espíritu burlón y periférico para la creación de Institutos. Aquel espíritu irreverente y desenfadado nacido en ese entorno de libertad se inocula en la genética de Institutos. Parece como si aquella conciencia periférica fuese un elemento catalizador de la categoría de lo fantástico-humorístico, tal y como lo piensan las autoras de Caniculadas. Encontraban, además, la complicidad de otras obras dentro de la misma colección, las cuales daban, de algún modo, una legitimidad editorial normalizando un discurso al formar parte de un plan mayor.

Sería erróneo, sin embargo, pensar que la emergencia de este fantástico-humorístico está en estricta dependencia de la mutación del espíritu de un blog en un libro colectivo. Existen algunos otros casos como los de Furillo con su obra Las cloacas de la Cripta (Autsider Comics, 2019), en la que se puede observar una reescritura paródica del cómic de terror sobre las bases del underground, lo que le da un sesgo grotesco a la par que humorístico. Con su Maldita casa encantada (Roca Editorial, 2019), Artur Laperla acomoda el relato de terror a una estructura narrativa que remeda las maneras de «elige tu propia aventura». Tampoco ignora el humor, que está engastado en la arquitectura terrorífica del relato. ${ }^{13}$

En esa variedad estratégica que muestra lo fantástico-humorístico parece haber un denominador común: el carácter periférico de esas realizaciones. En consonancia con ello puede entenderse que obras de lo fantástico creadas por autoras de cómic compartan también esa posición. ${ }^{14}$ Pienso en ejemplos como los de Anabel Colazo con El cristal imposible (Dehavilland Ediciones, 2015). ${ }^{15}$ Lo fantástico, que ocupaba un espacio fundamental en el boom

13 El propio autor lo reconoce en el seno de una entrevista en la que ofrece una pista sobre los precedentes que tiene en cuenta al respecto de la relación entre terror y humor: «Mi idea era hacer un tebeo de terror y de humor. Una lectura, ligera, divertida y truculenta a la vez. En un cómic en el que puedes morir varias veces has de dar un respiro al lector. De ahí el tono. Me gusta mucho el chiste malo que el tío Creepy suelta al final de cada historia. Y lo mejor de La hora de Alfred Hitchcock, para mí, es el principio y el final, esos detalles de humor negro frívolo. Me gusta el contraste entre humor y muerte» (Tones, 2019).

14 No solo el cómic fantástico ha sido refractario a la incorporación de la voz de la mujer. El otro polo -lo humorístico - tampoco ha sido un territorio propicio para la incorporación de la mujer como autora. Valgan las palabras de Mamen Moreu (integrante de Caniculadas) cuando afirma en el curso de una entrevista con Lluís Aznar: «En esa época [se refiere en torno a 2008] era raro ver a una mujer haciendo cómics de humor. En El Jueves solo habían publicado Maitena y Mariel Soria. Así que, si no me equivoco, yo fui la tercera mujer en dibujar para El Jueves. Tenía veinticuatro años» (Moreu, 2019: 141).

15 Ahí podría establecerse una lectura cruzada de la obra de Anabel Colazo con otras que forman parte de esa colección, como Safari Honeymoon de Jesse Jacobs. En ambas lo fantástico puede verse como un umbral hacia otro nivel de existencia: el encuentro de un cristal de imposible catalogación o la selva en la que una pareja pasa su luna de miel crean un marco para ingresar en otro nivel. De este modo puede uno llegar a preguntarse hasta qué punto el diseño editorial de colecciones conlleva —al menos en el mundo del cómic - una política de publicaciones que fomente una forma discursiva. 
del cómic en los años 70-80, se ha visto desplazado de algún modo hacia otras posiciones. Ese lugar secundario le ha permitido encarnar propuestas singularizadas y muy personales. La consecución de lo fantástico-humorístico, el nacimiento de una complicidad grupal de mujeres que unen lo cotidiano y el humor junto con el terror, el desmontaje y deflación de las leyendas urbanas parecen cartografiar un territorio fértil en la innovación creativa que se distancia de los cánones de representación de la mujer y de toda la iconografía de lo fantástico sólidamente acrisolada en las revistas del boom.

\section{CONCLUSIONES}

Institutos, del colectivo Caniculadas, presenta una estrategia fértil en la reescritura de lo fantástico desde otras ópticas, que podrían ser calificadas como ópticas de lo periférico. El espacio de lo digital permitía una gran libertad expresiva, pues no cuenta con filtros de intermediación como son las editoriales, la distribución, las librerías y todos aquellos elementos que intervienen en la comercialización. Esa libertad canaliza unas formas representativas basadas en la espontaneidad que, en lo iconográfico, presentan una idea de la mujer muy alejada de lo fantástico de las revistas del boom. La mujer no es un objeto deseable, un fetiche erótico, sino un sujeto que está construido visualmente desde la noción de la caricatura. Sirve esa forma de autorrepresentación como una toma de distancia irónica que permite, en lo temático, una coalición entre lo humorístico y lo fantástico. Esas inercias generadas en las lindes de lo digital se trasvasan en cierto modo a la política del mundo impreso. Para ello la editorial Astiberri generó una colección que diera cabida de forma natural a ese impulso que aunaba lo humorístico y lo fantástico a través de la leyenda urbana. Existe, no obstante, una diferencia entre lo fantástico aglutinado en el blog de Caniculadas y su realización del libro Institutos. Mientras que lo fantástico asociado a relatos de terror era un discurso que se «citaba» para contar elementos cotidianos o, dicho de otra manera, una retórica de segundo grado para construir una narración de algún suceso del día a día, lo fantástico se convierte en el núcleo esencial en Institutos. Precisamente en Institutos se consigue una equiparación estructural entre el gag humorístico y el relato terrorífico. Ambas formas narrativas se basan en la brevedad y albergan en su interior la necesidad de un giro inesperado.

Esa estructura polifónica causada por la sincronización estructural de dos discursos tan aparentemente enfrentados genera una riqueza de efectos 
de enorme interés, articulados en diferentes niveles enunciativos. Cuando una narradora cuenta una historia de miedo su auditorio actúa de forma subversiva, burlándose de los manidos tópicos de la leyenda urbana. En un giro argumental localizado en el final del relato nace un elemento que impacta y que borra la risa de ese grupo de muchachas. Cuando eso sucede y el miedo asoma a los personajes ficticios que han escuchado la historia, el lector capta, ahora y desde su pertenencia externa al mundo ficticio, esa forma humorística del relato: su risa —-me refiero a la del lector- nace del miedo de aquellas jóvenes adolescentes que se burlaban en un principio de la historia terrorífica que habían comenzado a escuchar. Podría verse así una estructura genérica modular en la que unos géneros van encajados dentro de otros. En los niveles profundos aquellos relatos nacían con una voluntad de causar miedo, si bien el contexto y la recepción reconducían ese impulso hacia lo humorístico. Ese giro inesperado opera un cambio de actitud en el grupo de muchachas y las risas se convierten en estupefacción y silencio. Cuando eso sucede el mensaje actúa desde un punto de vista pragmático en una doble dirección: para las jovencitas burlonas funciona como fuente de terror, en tanto que para el lector, y debido a ese mismo cambio, opera como un gag humorístico final. Se configura así una estructura de efectos cambiantes en los que el humor y el terror se van dando relevo. En lo más profundo, el texto nacía con una intención de aterrorizar y, finalmente y contra lo que era previsible, lo consigue; sin embargo, el lector acabará riéndose con las actitudes de esas jóvenes alocadas de tal forma que lo que nació bajo los designios de la leyenda urbana sobrevive en manos del lector y ya en terrenos de lo extradiegético como un gag humorístico. Esquemáticamente, tendríamos algo así:

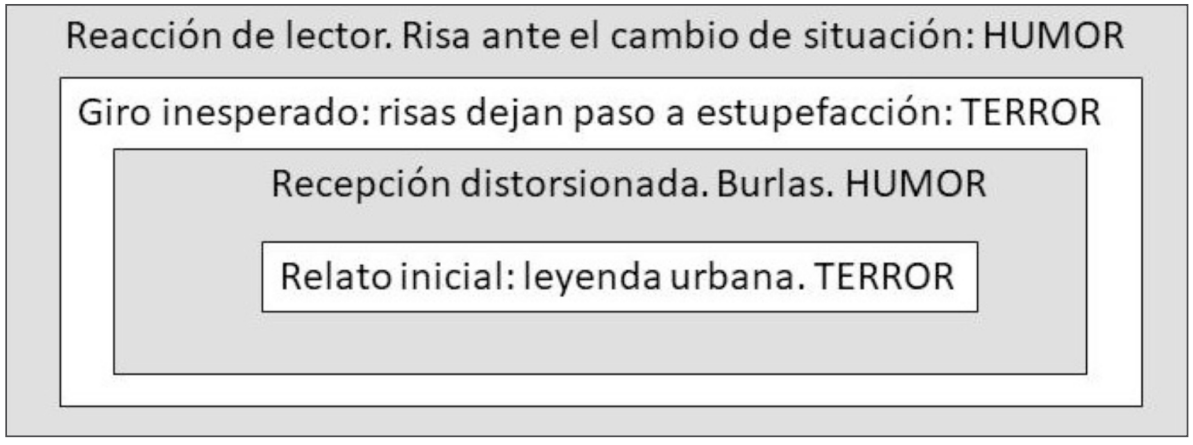

Tal disposición estructural genera una gramática en la que se van empastando las diversas historias. Para aunar los diferentes estilos gráficos se 
genera una koiné estilística que nace de una actitud colaborativa propia de los entornos digitales, pero que aquí viene apoyada sobre todo por la necesidad editorial de convertir las diferentes voces en un relato único, que debía ser insertado en el mercado editorial a través de un libro con una legibilidad estilística. Todo ello viene a afianzar una poética de lo fantástico desterritorializado, en el que unas jóvenes nos invitan a reírnos de nuestros miedos, conservando un pequeño resquicio para que lo inexplicable siembre sus raíces sobre las grietas de una realidad que está lejos de ser rocosa y monolítica.

BiBLIOGRAFÍA

Altarriba. Antonio (2001): La España del Tebeo. La historieta española de 1940 a 2000, Espasa-Calpe, Madrid.

- (2008): Los tebeos de la Transición, Cuadernos del Hocinoco, Cuenca.

Barreiro, Ricardo, \& Eduardo Risso (2004): Parque Chas, Puro Comic, Rosario.

BocutTI, Anna (ed.) (2018): El humor y lo fantástico, monográfico de Brumal. Revista de Investigación sobre lo Fantástico, vol. VI, núm. 1.

Bustos, Natacha (2014): «Los Souvenirs: Otra historia de terror», en Caniculadas 5.0, disponible en <http:/ / caniculadas.blogspot.com/2014/ 08/los-souvenirs-otra-historiade-terror.html> [15-09-2020].

Caniculadas (2014): Institutos, Astiberri, Bilbao.

Carroll, Nöel (2003): Beyond Aesthetics. Philosophical Essays, Cambridge University Press, Nueva York.

- (2005): Filosofía del terror o paradojas del corazón, trad. Gerard Vilar, Antonio Machado Libros, Madrid.

Claudio, Esther (2017): «De anzuelos y espejos o cómo encontrar la salida al laberinto de la alienación», Brumal. Revista de Investigación sobre lo Fantástico, vol. V, núm. 1, pp. 43-66. <https: / / doi.org/10.5565/ rev/brumal.356>

Colazo, Anabel (2015): El cristal imposible, Dehavilland Ediciones, Barcelona.

Cortijo, Adela (2011): «Autoras contemporáneas en la historieta española. Revisión de la etiqueta "cómic femenino"», Arbor, núm. 187, pp. 221-238. <https: / / doi. org/10.3989/arbor.2011.2extran2120>

Dark Horse Archives (2009): Eerie. Collecting Eerie, I, Dark Horse, Milwaukie.

Díaz de Guereñu, Juan Manuel (2011): «El cómic español desde 1995», Arbor, núm. 187, pp. 209-220.

- (2014): Hacia un cómic de autor. A propósito de Arrugas y otras novelas gráficas, Universidad de Deusto, Bilbao.

- (2019): «Relato de género y destino trágico en Antoine de las tormentas», en José Manuel Trabado Cabado (ed.), Género y conciencia autoral en el cómic español (19702018), Universidad de Léon-Eolas Ediciones, León, pp. 325-350. 
EC Comics (2019): Chope Gasp! The Best of 75 Years of EC Comics. A Selection of Handpicked EC Comics Stories, Dark Horse, Milwaukie.

Furillo (2019): Las Cloacas de la cripta, Autsider Cómics, Sineu.

GarcíA, Patricia (2019a): «Introduction: Gender and the Hispanic Fantastic», Bulletin of Hispanic Studies, vol. 96, núm. 6, pp. 569-574. <https://doi.org/10.3828/ bhs.2019.33>

— (2019b): «Spanish and Latin American Women Writers in the Literary Canon: A Paratextual Study of Anthologies of Fantastic Literature», Bulletin of Hispanic Studies, vol. 96, núm. 6, pp. 575-593. <https: / / doi.org/10.3828/bhs.2019.34>

GASCA, Luis, \& Román Gubern (2015): El universo fantástico del cómic, Cátedra, Madrid.

Guiral, Antoni (2011): «1970-1995: un reloj atrasado y otro tren perdido», Arbor, 187, pp. 183-208. <https: / doi.org/10.3989/arbor.2011.2extran2118>

- (2016): «Aproximación a una genealogía de la mujer historietista en el comic español: de los inicios al boom de las revistas», en Colectivo de Autoras de Cómic, Elisa McCausland \& Carla Berrocal (coords.), Presentes: autoras de tebeo de ayer y hoy, Agencia Española de Cooperación Internacional para el Desarrollo, Madrid, pp. 10-22.

JiMÉNEZ VAREA, Jesús (2003): «El horror como categoría editorial en los comic books previos al Comics Code», en Jorge D. Fernández, Jesús Jiménez \& Antonio Pineda (eds.), El terror en el cómic, Comunicación Social, Ediciones y Publicaciones, Sevilla, pp. 53-92.

LAPERLA, Artur (2019): Maldita casa encantada, Roca Editorial, Barcelona.

McCausland, Elisa, \& Diego Salgado (2019): Supernovas. Una historia feminista de la ciencia ficción audiovisual, Errata Naturae, Madrid.

Merino, Ana (2016): «El eje femenino americano y la consolidación de sus miradas», en Colectivo de Autoras de Cómic, Elisa McCausland \& Carla Berrocal (coords.), Presentes: autoras de tebeo de ayer y hoy, Agencia Española de Cooperación Internacional para el Desarrollo, Madrid, pp. 25-36.

Microlocas (2016): Pelos, Páginas de Espuma, Madrid.

Monteys, Albert (2014): Misterios comestibles. Ratas. Fast food y otras delicatesen, Astiberri, Bilbao.

Moreu, Mamen (2019): «Entrevista con Lluís Aznar», en Lluís Aznar \& al. (eds.), El humor gráfico, Diminuta Editorial, Barcelona, pp. 137-154.

Pérez, Pepo (2018): «¿“Solo para adultos”? Del boom al crack. La ficción de género en las revistas españolas de cómic de los ochenta», en Gerardo Vilches (ed.), Del Boom al Crack. La explosión del cómic adulto en España (1977-1995), Diminuta Editorial, Barcelona, pp. 57-92.

Prado, Miguelanxo (2006): Belo Horizonte, Norma Editorial, Barcelona.

RoAs, David (2011): Tras los límites de lo real. Una definición de lo fantástico, Páginas de Espuma, Madrid.

SÁNCHEZ, David (2013): Videojuegos, Astiberri, Bilbao.

SERrAnO, José Antonio (2016). «Webcómics en España hoy: breve guía de campo», en Pepo Pérez (coord.), Comic digital hoy. Una introducción en presente. <http:/ / www.acd comic.es / comicdigitalhoy / 05-Webcomics-Espana-Jose-A-Serrano-acdcomic.pdf $>$ [23-10-2020]. 
Todorov, Tzvetan (1972): Introducción a la literatura fantástica, trad. Silvia Delpy, Tiempo Contemporáneo, Buenos Aires.

TONES, John (2019): «Artur Laperla, autor de Maldita casa encantada: "Mi idea era hacer una lectura ligera, divertida y truculenta"», Canino, 9 de abril <https: / / www. caninomag.es / artur-laperla-autor-de-maldita-casa-encantada-mi-idea-era-hacer-una-lectura-ligera-divertida-y-truculenta / > [Fecha de consulta: 25-9-2020].

Tormo, Bea (2015): «Terrorific Summer», en Caniculadas 5.0, disponible en <http:/ / caniculadas.blogspot.com / 2015/08/terrorific-sumer.html> [12-09-2020].

Torrejón, Andrea (2015): «Los lunes de mierda II: CLIENTES DE MIERDA», en Caniculadas 5.0, disponible en <http: / / caniculadas.blogspot.com.es/2015/07/loslunes-de-mierda-ii-clientes-de.html> [Fecha de consulta: 12-9-2020].

TRABADO, José Manuel (2017a): «La narración gráfica. 1900-2015», en David Roas (dir.), Historia de lo fantástico en la cultura española (1900-2015), Iberoamericana/Vervuert, Madrid/Frankfurt am Main, pp. 351-380.

- (ed.) (2017b): Lo fantástico en los cómics, monográfico de Brumal. Revista de Investigación sobre lo Fantástico, vol. V, núm. 1.

- (2019): «Miguelanxo Prado: un proyecto narrativo llamado autor», en José Manuel Trabado Cabado (ed.), Género y conciencia autoral en el cómic español (1970-2018), Universidad de León-Eolas Ediciones, Léon, pp. 129-177.

VARILLAS, Rubén (2016): «De la revolución del cómic y otros augurios», en Pepo Pérez (coord.), Comic digital hoy < https: / / www.acdcomic.es / comicdigitalhoy / 02-Revolucion-del-comic-Ruben-Varillas-acdcomic.pdf $>$ [23-10-2020].

VAx, Louis (1965): Arte y literatura fantásticas, trad. Juan Merino, Eudeba, Buenos Aires. VILA, Marika (2018): «Las autoras españolas en el boom del cómic adulto. La mordaza patriarcal y el silencio roto», en Gerardo Vilches (ed.), Del Boom al Crack. La explosión del cómic adulto en España (1977-1995), Diminuta Editorial, Barcelona, pp. 203-228.

VilCHES, Gerardo (2016): «El final del verano. Una entrevista a Caniculadas», en Pepo Pérez (coord.), Comic digital hoy, <http:/ / www.acdcomic.es/comicdigitalhoy/19-Caniculadas-entrevista-Gerardo-Vilches-acdcomic.pdf $>$ [19-10-2020].

Wright, Bradford W. (2003): Comic Book Nation. The Transformation of Youth Culture in America, John Hopkins University Press, Baltimore \& Londres. 